Check for updates

Cite this: RSC Adv., 2018, 8, 16410

\title{
Intermittent time-set technique controlling the temperature of magnetic-hyperthermia-ablation for tumor therapy $\dagger$
}

\author{
Xiuzhen Tang,,$^{\mathrm{ab}}$ Yanjun Xu,,$^{\mathrm{b}}$ Jie Chen, ${ }^{\mathrm{b}}$ Tao Ying, ${ }^{\mathrm{b}}$ Longchen Wang, ${ }^{\mathrm{b}}$ Lixin Jiang, ${ }^{\mathrm{b}}$ \\ Yan Wang, ${ }^{b}$ Zhenhai Wang, ${ }^{c}$ Yi Ling, ${ }^{a}$ Fengjuan Wang, ${ }^{a}$ Li Yao, ${ }^{b}$ Haitao Ran, ${ }^{a}$ \\ Zhigang Wang, ${ }^{a}$ Bing $\mathrm{Hu}^{* \mathrm{~b}}$ and Yuanyi Zheng (ID*ab
}

\begin{abstract}
Magnetic-hyperthermia-ablation is considered as an effective and minimally invasive technology for tumor therapy. However, inappropriate temperature control could induce an excessively high temperature which brings potential safety problems and limits clinical transformation of this technique. Herein, aiming to control the temperature during magnetic hyperthermia ablation, we develop an intermittent time-set technique for temperature control in magnetic hyperthermia ablation of tumors using a polylactic-coglycolic acid (PLGA)- $\mathrm{Fe}_{3} \mathrm{O}_{4}$ implant. In vitro, the intermittent time is set as follows: tubes are continuously heated for 110 seconds. Then the heating process is paused for 20 seconds, and then the tubes are reheated for 10 seconds, followed by repeating the last two processes. The temperature elevation profile upon magnetic hyperthermia interestingly also demonstrates good controllability despite some differences in time-setting between in vitro and in vivo. The in vivo results show the temperature fluctuates within the range of $6.45 \pm 1.34{ }^{\circ} \mathrm{C}$ after reaching the target temperature. Furthermore, we observe the deformation of an implant employing three-dimensional (3D) ultrasound to better understand the temperature change. The results show no significant deformation of the implant after being heated. The microscopic images prove that this simple technique can successfully cause tumor regression. This temperature control technique provides great benefits for hyperthermia ablation against tumors, advancing the magnetic hyperthermal ablation technology in clinical translation.
\end{abstract}

\author{
Received 6th February 2018 \\ Accepted 30th March 2018 \\ DOI: $10.1039 / c 8 \mathrm{ra01176a}$ \\ rsc.li/rsc-advances
}

\section{Introduction}

Hyperthermal ablation is considered as one of the powerful and minimally invasive therapies for tumors. ${ }^{1,2}$ The hyperthermia ablation techniques including radiofrequency, microwave ablation and high intensity focused ultrasound (HIFU), are the three main applied clinical techniques..$^{3-5}$ Nonetheless, these traditional strategies have some limitations, such as severe trauma, transient pain and skin burns, which may restrict their broad clinical applications. Therefore, it is of great significance to develop a new efficient strategy to satisfy the clinical need. Magnetic hyperthermia is an alternative efficient hyperthermal ablation for tumor therapy. When exposed to the alternating

\footnotetext{
${ }^{a}$ Institute of Ultrasound Imaging, Second Affiliated Hospital of Chongqing Medical University, Chongqing, 400010 PR China

${ }^{b}$ Department of Ultrasound \& Department of Biomedical Engineering, Shanghai Jiao Tong University Affiliated Sixth People's Hospital, Shanghai, 200233 PR China. E-mail:Binghu_stan@163.com; zhengyuanyi@163.com

${ }^{c}$ General Hospital of Ningxia Medical University, Ningxia, 750004 PR China

$\dagger$ Electronic supplementary information (ESI) available. See DOI: 10.1039/c8ra01176a

$\$$ These authors contributed equally to this work.
}

magnetic field (AMF), magnetic materials in the site of tumor can convert electromagnetic energy into heat, causing the increasing temperature of tumor to induce the death of tumor cells. ${ }^{1-3}$ Magnetic hyperthermia has become a multidiscipline research field including physics, chemistry, material science and medical science, ${ }^{4}$ which involves drug release, remote control of single-cell functions, plasmonic devices, hyperthermia therapy of cancer and other diseases. ${ }^{5}$ What is more, magnetic hyperthermal ablation has been applied in its clinical grade as a stand-alone therapy for glioblastoma and prostate cancer. ${ }^{6,7}$ Magnetic hyperthermia can especially deal with deepseated tumors without depth limitation.

Magnetic nanoparticles are developing as a vital class of multifunctional biomedical materials in areas such as hyperthermia, ${ }^{8}$ drug release, ${ }^{9}$ tissue engineering, ${ }^{10}$ photothermia ${ }^{11}$ and other theranostics ${ }^{12}$ due to their unique chemical and physical properties. The most popular magnetic nanoparticles in the biomedical field are transition metal oxide, and some ferrites $\left(\mathrm{BaFe}_{12} \mathrm{O}_{19}\right.$ and $\left.\mathrm{CoFe}_{2} \mathrm{O}_{4}\right) \cdot{ }^{13-15}$ Among them, iron oxide nanoparticles $\left(\mathrm{Fe}_{2} \mathrm{O}_{3}\right.$ or $\left.\mathrm{Fe}_{3} \mathrm{O}_{4}\right)$ are the most commonly used because of their good biosafety. They can be delivered to the tumor through four different methods ${ }^{15}$ i.e. the arterial injection, intravenous injection, the direct injection into the tumor 
region, and the in situ implant formation using entrapped nanoparticle gel. Unlike solid materials, the flowing nanoparticles have the potential to penetrate into blood circulation system, causing long-term toxic reactions, ${ }^{16,17}$ In order to reduce this potential side effect of materials, our group selected the last approach, combining Fe and PLGA. ${ }^{18}$ The injectable smart phase-transformation Fe/PLGA implants were designed for highly efficient in vivo magnetic-hyperthermia regression of tumors. ${ }^{19}$ Inspired by the strong synergistic effect between chemotherapy and magnetic hyperthermia, ${ }^{\mathbf{2 0 - 2 2}}$ our group developed an efficient strategy which combines magnetic hyperthermia with anti-cancer drug (e.g. DOX and DDP). ${ }^{23,24}$ However, it is still troublesome to control the increasing temperature during magnetic hyperthermia ablation. Excessively high temperature always occurs during the treatment of magnetic hyperthermal ablation, inducing damage to healthy tissue around tumor and other adverse effects including morbidity and injury, which will hinder their clinical translation.

There are a lot of influence factors, e.g. coil size, the frequency and the field strength of AMF, and the physicochemical property of magnetic particle, which make it complicated to control the increasing temperature during the process of magnetic hyperthermia. ${ }^{25,26}$ For example, the small coil size is not suitable for big body, and there exists a safety limit, $H^{*} f<5$ $\times 10^{9} \mathrm{Am}^{-1} \mathrm{~S}^{-1},{ }^{31,32}$ which is empirically imposed on the AMF to protect the body fluid from inducing eddy current in clinical applications. ${ }^{27,28}$ Although the research devotes to avoid the problem of the need of using high doses of nanoparticles to produce a sufficient heating, which exploits the nanoparticles as "hot spots" sources able to trigger locally cellular responses in the absence of a global temperature rise. ${ }^{29}$ It is also inconvenient to control the temperature by the material dosage. The large dosage of magnetic particle can induce excessively high temperature. $^{30}$ While the smaller dosage cannot generate enough heat to kill cancer cells. Therefore, it is complicated to master the physicochemical property of magnetic particle to maintain the enhanced temperature during the process of magnetic hyperthermia. ${ }^{31}$

Taking these limitations into consideration, herein, we designed a simple intermittent time-set technique for controlling the enhanced temperature during the process of magnetic hyperthermia to reduce the side effect based on polylactic- $\mathrm{co}^{-}$ glycolic acid (PLGA)- $\mathrm{Fe}_{3} \mathrm{O}_{4}$ implant. With the aid of this technology, the system can generate heat quickly to make the target site with the appropriate temperature, and maintain the enhanced temperature for needed time. As shown in (Scheme 1), once the tumor temperature reaches the targeted, the intermittent "on-off" of magnetic field is promptly used to maintain the temperature. Thermal camera is chosen to monitor the changing temperature. With the aid of this intermittent treatment, the disadvantage of excessive high temperature could be overcome easily, which can efficiently reduce the damage to healthy tissue during the process of magnetic hyperthermia. This simple but efficient strategy may be beneficial for the development of magnetic hyperthermal ablation in clinic.

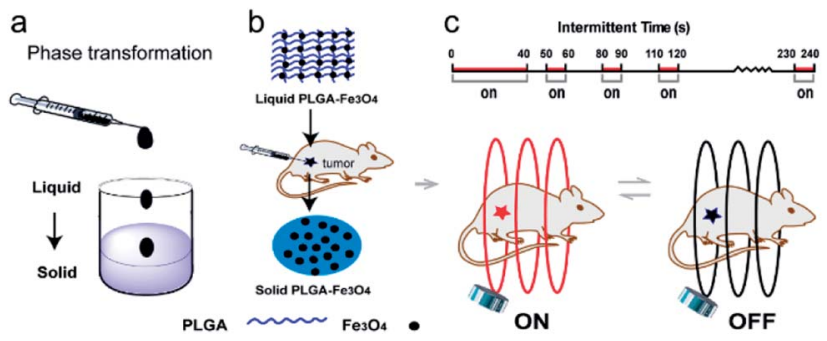

Scheme 1 Injectable PLGA- $\mathrm{Fe}_{3} \mathrm{O}_{4}$ for the magnetic-hyperthermia ablation of tumor. (a) Phase transformation process of implant. (b) Injection of the liquid PLGA- $\mathrm{Fe}_{3} \mathrm{O}_{4}$ into the tumor center. (c) Schematic illustration of corresponding intermittent-time setting. Temperature dynamics during the on-off switching of AMF. PLGA$\mathrm{Fe}_{3} \mathrm{O}_{4}$ inside the tumor under AMF: the red color coil represents the heating process, the black coil represents the pause time.

\section{Materials and methods}

\section{Preparation of PLGA-Fe ${ }_{3} \mathrm{O}_{4}$ implant}

Typically, polylactic-co-glycolic acid (PLGA, $M_{\mathrm{w}}: 40000 \mathrm{Da}, 50$ : 50, $1.1 \mathrm{~g}$, Jinan Daigang Bioengineering Co., Ltd) was put into a beaker, followed by adding $N$-methyl pyrrolidone (NMP, $2 \mathrm{~mL}$, Sigma-Aldrich). The weight ratio of PLGA and NMP liquid was $1.1 \mathrm{~g}$ : $2 \mathrm{ml}$. The PLGA was successfully dissolved into NMP at $37^{\circ} \mathrm{C}$, $100 \mathrm{rpm}$ overnight to obtain a light yellow homogeneous PLGA liquid gel. Then, $\mathrm{Fe}_{3} \mathrm{O}_{4}$ nanoparticles (Chengdu Aike Chemical Reagent Co., Ltd) with an average diameter of 20-50 nm, were mixed via mechanical stirring according to the certain proportion. Three kinds of implants were prepared by mixing the PLGA, NMP liquid with different proportions of iron oxide and the mass ratio of $\mathrm{Fe}_{3} \mathrm{O}_{4}$ was 1.0, 2.0 and 3.0, respectively (Table 1).

\section{Structure characteristics and liquid-solid phase transformation ability of PLGA-Fe $\mathrm{F}_{3} \mathrm{O}_{4}$}

PLGA- $\mathrm{Fe}_{3} \mathrm{O}_{4}$ implant was made of PLGA and $\mathrm{Fe}_{3} \mathrm{O}_{4}$ nanoparticles. The microstructure of PLGA- $\mathrm{Fe}_{3} \mathrm{O}_{4}$ was tested by using scanning electron microscope (SEM, JEOC-7800F). And the element analysis was observed by an energy dispersive X-ray spectrometer (EDS). The liquid $\mathrm{PLGA}^{-} \mathrm{Fe}_{3} \mathrm{O}_{4}$ was poured into a $1 \mathrm{~mL}$ syringe. Then the $\mathrm{PLGA}-\mathrm{Fe}_{3} \mathrm{O}_{4}$ was injected into the water to observe the progress of liquid-solid phase transformation.

\section{Evaluations of magnetic properties of $\mathrm{Fe}_{3} \mathrm{O}_{4}$ nanoparticles and $\mathrm{PLGA}-\mathrm{Fe}_{3} \mathrm{O}_{4}$ powder}

Heating tumors with magnetic materials by magnetic hyperthermia was based on Neel and Brownian relaxation. In the

Table 1 The corresponding percentage of all components

\begin{tabular}{|c|c|c|c|}
\hline \multirow[b]{2}{*}{ Sample } & \multicolumn{2}{|c|}{ Powder (wt\%) } & \multirow{2}{*}{$\begin{array}{l}\text { liquid } \\
\text { (wt\%) }\end{array}$} \\
\hline & $\mathrm{Fe}_{3} \mathrm{O}_{4}$ & PLGA & \\
\hline PLGA-0 & 0 & 34.85 & 65.15 \\
\hline PLGA-10\% $\mathrm{Fe}_{3} \mathrm{O}_{4}$ & 10 & 31.37 & 58.63 \\
\hline PLGA-20\% $\mathrm{Fe}_{3} \mathrm{O}_{4}$ & 20 & 27.88 & 52.12 \\
\hline PLGA-30\% $\mathrm{Fe}_{3} \mathrm{O}_{4}$ & 30 & 24.40 & 45.60 \\
\hline
\end{tabular}


presence of an external AMF, the magnetic moment rotated and the material itself rotated, then relaxed back to original magnetic field orientation. This orientation of magnetic moment (Neel mode) and the friction arising from particle oscillations (Brownian mode) led to a phase lag between applied magnetic field and the direction of the magnetic moments. As a result, the heat was generated. So in order to assess the heating ability of PLGA- $\mathrm{Fe}_{3} \mathrm{O}_{4}$ implant, the magnetic properties of $\mathrm{Fe}_{3} \mathrm{O}_{4}$ and $\mathrm{PLGA}-\mathrm{Fe}_{3} \mathrm{O}_{4}$ powder were tested by Physical Property Measurement System (PPMS-9) at room temperature. PPMS was developed by Quantum Design which can be used to measure the basic physical properties of materials.

\section{In vitro temperature elevation profile upon magnetic hyperthermia}

For the in vitro assay, three types of liquid PLGA-Fe ${ }_{3} \mathrm{O}_{4}(60 \mu \mathrm{L})$ containing various amounts of $\mathrm{Fe}_{3} \mathrm{O}_{4}$ powder $(10 \%, 20 \%, 30 \%)$, and different volumes $(40 \mu \mathrm{L}, 60 \mu \mathrm{L}, 80 \mu \mathrm{L})$ were put into saline solution $(1.5 \mathrm{~mL})$ in tubes $(2 \mathrm{~mL})$. The tubes were put in the center of the electromagnetic induction heating coil of a homemade magnetic hyperthermia analyzer (frequency: 513 $\mathrm{kHz}$, output current: $28.2 \mathrm{~A}$, output voltage: $361 \mathrm{~V}$, coil diameter: $10 \mathrm{~cm}$, output power: $8 \mathrm{~kW}$ ). The inductor heating coils were cooled using a closed loop circulating water system during operation. When the tubes were exposed to AMF for three minutes, infrared thermal video of the tubes were simultaneously recorded at one picture per second. Subsequently, the tubes containing only saline solution was used under the same conditions as the blank control. The temperatures of the saline solution were analyzed using the thermal video by AnalyzIR software. Last but not the least, based on above experiments, different volumes of $40 \mu \mathrm{L}, 60 \mu \mathrm{L}, 80 \mu \mathrm{L}$ PLGA-20\% $\mathrm{Fe}_{3} \mathrm{O}_{4}$ were chosen for being heated by the specific intermittent mode. At the beginning of this study, a lot of experiments using different heating exposure time parameters were carried out. According to the characteristics of rising and falling during the heating process, the relevant on-off time was designed. The most appropriate condition was ultimately generated from these preliminary results. Namely, the tubes were continuously heated for 110 seconds. Then the heating paused for 40 seconds, and the tubes were reheated for 10 seconds. Afterwards, the last two processes were repeated. The data analysis method was the same as above. All data were performed in triplicate.

\section{Heating efficiency in excised bovine liver}

According to the above experiments, the $60 \mu \mathrm{L}$ PLGA-20\% $\mathrm{Fe}_{3} \mathrm{O}_{4}$ was selected for next experiment. Liquid implants were injected into the excised bovine liver pieces $(2 \mathrm{~cm} \times 2 \mathrm{~cm} \times 2 \mathrm{~cm})$. The fresh excised bovine liver was obtained from a slaughterhouse (The ocean dairy farm in NO.5 Jinsheng road, Dayao town, Jiashan country, Zhejiang province, China). An hour later, the excised bovine liver pieces was moved to the alternating current magnetic field generated by a homemade magnetic hyperthermia machine (frequency: $513 \mathrm{kHz}$, output current: $28.2 \mathrm{~A}$, output voltage: $361 \mathrm{~V}$, coil diameter: $10 \mathrm{~cm}$, output power: 8
$\mathrm{kW}$ ). Due to the difference between water and excised bovine liver, the intermittent mode of heating was correspondingly adjusted. First, excised bovine liver pieces were continuously heated for 40 seconds. Subsequently, the heating process paused for 10 seconds, and the tissues were reheated for 10 seconds. Then the heating process paused for 20 seconds, and the last two processes were repeated. The surface temperature of bovine liver pieces was acquired by a far-infrared thermometer (Fotric). The thermal images were analyzed using the AnalyzIR Software as well. The conventional continuously heating of excised bovine liver pieces was conducted for making a comparison.

According to the above experiments, the coagulation necrosis area of implant was studied at different exposure time (1, 2, 3 and 5 minutes). $60 \mu \mathrm{L}$ PLGA-20\% $\mathrm{Fe}_{3} \mathrm{O}_{4}$ was implanted into the excised bovine liver pieces $(2 \mathrm{~cm} \times 2 \mathrm{~cm} \times 2 \mathrm{~cm})$ and exposed to the same alternating current magnetic field for the same heating manner as above. Then, the excised bovine liver was split into two parts and the coagulation necrosis area was measured by ruler. Based on the following formula, the area was calculated.

$$
S_{1}=\pi D_{1} D_{2}
$$

where $S_{1}$ is the coagulation necrosis area $\left(\mathrm{cm}^{2}\right), D_{1}(\mathrm{~cm})$ and $D_{2}$ $(\mathrm{cm})$ is the long and short diameter.

\section{Nude mice MDA-MB-231 human breast cancer xenograft}

Eighteen SPF female nude mice (4 weeks old, $19.3 \pm 0.8 \mathrm{~g}$ ) were obtained from the Experimental Animal Center of Shanghai Jiao Tong University Affiliated Sixth People's Hospital (Shanghai, China). All the procedures regarding animal maintenance and experiments are in strict accordance with the policy of the Institutional Animal Care and Use Committee (IACUC) of Shanghai Jiaotong University affiliated Shanghai sixth people's hospital. The IACUC has approved this study. All surgery was performed under pentobarbital sodium injection anesthesia, and all efforts were made to minimize suffering. MDA-MB-231 breast cancer cells (purchased from the Chinese Academy of Sciences, Shanghai, China) were collected by centrifugation, dispersed into L-15 cell culture medium and $1 \times 10^{5}$ cells were injected into the right back of each nude mouse subcutaneously. After 4 weeks, the tumor volume reached $0.453 \pm 0.109$ $\mathrm{cm}^{3}$. These tumor-bearing mice were used for the next experiment.

\section{In vivo 3D ultrasound/CT imaging}

The nude mice bearing the MDA-MB-231 xenograft were firstly anesthetized using pentobarbital (0.10-0.15 mL, 1\%). The point of the syringe was inserted into the tumor center under ultrasound guidance (Siemens Acuson S2000, Siemens, Germany). Subsequently, $60 \mu \mathrm{L}$ of liquid PLGA-20\% $\mathrm{Fe}_{3} \mathrm{O}_{4}$ was injected slowly. The implant echoes were monitored in situ and in real time via ultrasound. After that, the 3D ultrasound and CT images (Quantum FX, Perkinelmer) were acquired to observe the position of implant when the treatment finished. 


\section{In vivo magnetic hyperthermia of tumor eradication}

The eighteen nude mice bearing the MDA-MB-231 were divided into three groups. For group I, six nude mice were selected randomly and were anesthetized by pentobarbital (0.10-0.15 mL per mouse, 1\%). $60 \mu \mathrm{L}$ PLGA-20\% $\mathrm{Fe}_{3} \mathrm{O}_{4}$ was injected into the tumor tissues under the ultrasound guidance (Siemens Acuson S2000, Siemens, Germany). The condition of magnetic hyperthermia machine was the same as in vitro experiments (frequency: $513 \mathrm{kHz}$, output current: $28.2 \mathrm{~A}$, output voltage: $361 \mathrm{~V}$, coil diameter: $10 \mathrm{~cm}$, output power: 8 $\mathrm{kW}$ ). Because of the difference between water and tumor, the intermittent time was changed a little. In vivo, the intermittent time-set technique was the same as the excised bovine liver pieces experiments: the target tissues were uninterruptedly heated for 40 seconds. Later, the heating process paused for 10 seconds, and the tissues were reheated for 10 seconds. Subsequently, the heating process paused for 20 seconds, and the last two processes were repeated. Finally, the nude mice were exposed only once to the alternating current magnetic field for 4 minutes by that way and the temperature of tumor was obtained by infrared thermometer. For group II, six nude mice received continuously heating for comparing. When the temperature exceed about $90{ }^{\circ} \mathrm{C}$, the mice would easily awake from anesthesia and try to get rid of the heating coils. Considering for the relevant animal welfare, the heating time was controlled within two minutes to avoid excessive skin burn and miserable pains caused by continuously heating beyond two minutes. For group III, six nude mice that received no heating treatment were set as the blank control group. To acquire the microstructure of ablated tumors, three nude mice in each group were euthanized in 24 hours after treatment. Hematoxylin and eosin (HE) staining was performed for pathological examination. The rest of animals were under a carefully observation to keep a record of their weights, tumor volume and activities every day.

Evaluation of blood flow perfusion after ablation by contrastenhanced ultrasonography

The nude mice bearing the MDA-MB-231 xenograft were firstly anesthetized using pentobarbital (0.10-0.15 mL, 1\%). Firstly, $100 \mu \mathrm{L}$ SonoVue (Bracco, Italy) were injected via intravenous administration recorded by ultrasound (Siemens Acuson S2000, Siemens, Germany, MI: 0.08, MIF: 0.06, $4.00 \mathrm{MHz}$ ) in real-time to evaluate the tumor's blood perfusion. Secondly, 60 $\mu \mathrm{L}$ PLGA-20\% $\mathrm{Fe}_{3} \mathrm{O}_{4}$ was injected into the tumor tissues. 100 $\mu \mathrm{L}$ SonoVue were injected half an hour later, which enabled us to observe the influence of the implant on tumor. After the nude mice were exposed to the alternating current magnetic field, the equal volume SonoVue were injected in vein to record the results.

\section{Statistical analysis}

Statistical analysis was performed using SPSS 18.0 software. Error bars define the standard error of the mean.

\section{Results and discussion}

Characteristics and liquid-solid phase transformation ability of PLGA-Fe $\mathrm{F}_{3} \mathrm{O}_{4}$

In order to prepare PLGA-Fe ${ }_{3} \mathrm{O}_{4}$ implant, PLGA was firstly dissolved into NMP overnight, then $\mathrm{Fe}_{3} \mathrm{O}_{4}$ particles were added into the above liquid by mechanical stirring. As shown in the SEM images (Fig. 1b), the surface of the implant was rough. The $\mathrm{Fe}_{3} \mathrm{O}_{4}$ nanoparticles distributed evenly in PLGA gel. The elemental mapping analysis of $\mathrm{PLGA}-\mathrm{Fe}_{3} \mathrm{O}_{4}$ showed that every element was well dispersed in PLGA. As shown in (Fig. 1c), three elements including Fe, $\mathrm{C}$ and $\mathrm{O}$, were distributed on the whole surface of the implants, which clearly confirmed the successful preparation of $\mathrm{PLGA}-\mathrm{Fe}_{3} \mathrm{O}_{4}$. Moreover, liquid PLGA- $\mathrm{Fe}_{3} \mathrm{O}_{4}$ could be injected from syringe in the photographic images (Fig. $\mathrm{S} 1 \dagger$ ). When contacting with water, PLGA- $\mathrm{Fe}_{3} \mathrm{O}_{4}$ changed from liquid into solid immediately, instead of disintegrating in fragments and dispersing in water. These data proved that the injectable liquid-solid in situ phase-transformation PLGA-Fe ${ }_{3} \mathrm{O}_{4}$ implant was successfully synthesized. Besides, due to the PLGA-Fe ${ }_{3} \mathrm{O}_{4}$ quickly changing from liquid into solid, $\mathrm{Fe}_{3} \mathrm{O}_{4}$ nanoparticles were quickly located inside the implant. Therefore, $\mathrm{Fe}_{3} \mathrm{O}_{4}$ nanoparticles can accurately ablate tumor tissues and hardly leak from the tumor into the surrounding tissue or blood vessels, avoiding the decrease of heating efficiency.

\section{Magnetic properties of $\mathrm{Fe}_{3} \mathrm{O}_{4}$ particles and PLGA-Fe $\mathrm{O}_{3}$ powder}

In order to demonstrate if the implant could efficiently generate enough heat, we studied magnetic properties of pure $\mathrm{Fe}_{3} \mathrm{O}_{4}$ particles and $\mathrm{PLGA}-\mathrm{Fe}_{3} \mathrm{O}_{4}$ powder. Theoretically, the efficiency of generating heat strongly depends on specific absorption rate (SAR), and SAR depends on saturation magnetization value $\left(M_{\mathrm{S}}\right)$.

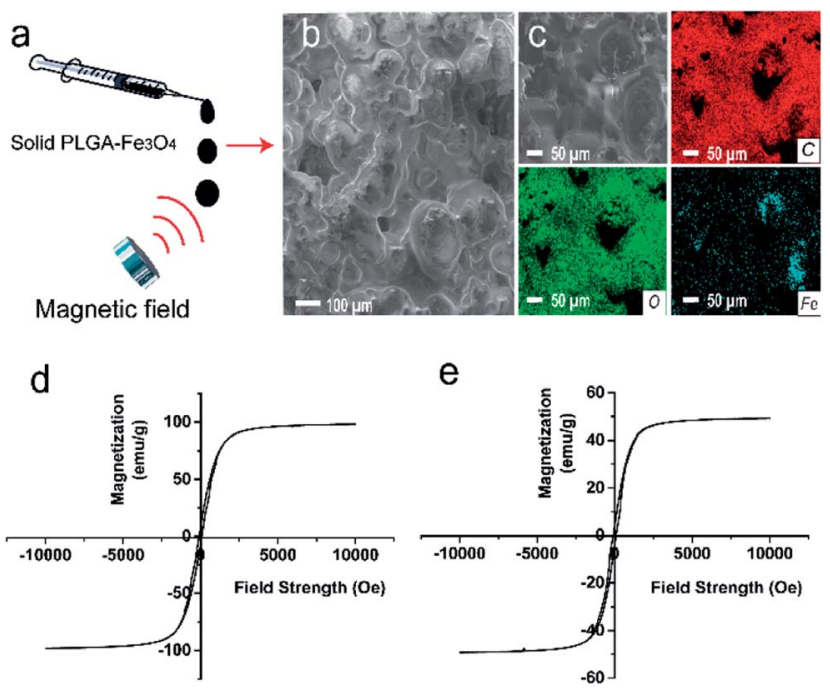

Fig. 1 Characteristics and magnetic properties. (a) Schematic of the phase transition of PLGA- $\mathrm{Fe}_{3} \mathrm{O}_{4}$. (b) SEM images of the rough surface PLGA- $\mathrm{Fe}_{3} \mathrm{O}_{4}$ implant. (c) Corresponding elemental mappings of solid PLGA- $\mathrm{Fe}_{3} \mathrm{O}_{4}$ implants. (d) The hysteresis curve of pure $\mathrm{Fe}_{3} \mathrm{O}_{4}$ nanoparticles. (e) The hysteresis curve of PLGA- $\mathrm{Fe}_{3} \mathrm{O}_{4}$ implant. 
The hysteresis curve (Fig. 1d and e) showed that both the pure $\mathrm{Fe}_{3} \mathrm{O}_{4}$ nanoparticles and the PLGA- $\mathrm{Fe}_{3} \mathrm{O}_{4}$ were ferromagnetic. The $M_{\mathrm{S}}$ of the pure $\mathrm{Fe}_{3} \mathrm{O}_{4}$ nanoparticles were $73 \mathrm{emu} / \mathrm{g}$, while the PLGA-Fe $\mathrm{O}_{3}$ had an $M_{\mathrm{s}}$ of $43 \mathrm{emu} / \mathrm{g}$. The presence of PLGA accounted for the decreased value of $M_{\mathrm{s}}$. But this saturation magnetization value was still high enough to guarantee that PLGA- $\mathrm{Fe}_{3} \mathrm{O}_{4}$ can generate enough heat for tumor therapy.

\section{Heating efficiency in vitro magnetic thermal property of PLGA- $\mathrm{Fe}_{3} \mathrm{O}_{4}$}

In order to pick out the suitable content of material, we prepared different concentrations and volume in that the heating efficiency is related to these basic factors. Both the exposure time and the changing temperatures of the implant were recorded for observing the trend of rising temperature. When the magnetic machine was turned off, both the downtrend of temperature and the time needed to reduce the temperature by one degree centigrade were also recorded in detail.

According to these elementary experiments, considerable number of in vitro experiments of various heating intermittent time using different content of $\mathrm{Fe}_{3} \mathrm{O}_{4}$ were carried out. As illustrated in (Fig. 2a), the $\mathrm{Fe}_{3} \mathrm{O}_{4}$ concentrations played an important role in heat generation. In the control group, the temperature of pure PBS did not change as time went on. The curve showed that the temperature of PLGA-20\% $\mathrm{Fe}_{3} \mathrm{O}_{4}$ reached $54.25 \pm 1.20{ }^{\circ} \mathrm{C}$ at 180 seconds, while the temperatures of PLGA$10 \% \mathrm{Fe}_{3} \mathrm{O}_{4}$ and PLGA-30\% $\mathrm{Fe}_{3} \mathrm{O}_{4}$ were $51.00 \pm 7.50{ }^{\circ} \mathrm{C}$ and 89.83 $\pm 3.10{ }^{\circ} \mathrm{C}$, respectively. These data indicated the heating efficiency was positively related to the mass fraction of $\mathrm{Fe}_{3} \mathrm{O}_{4}$. So, PLGA-20\% $\mathrm{Fe}_{3} \mathrm{O}_{4}$ was selected in the experimental group due to
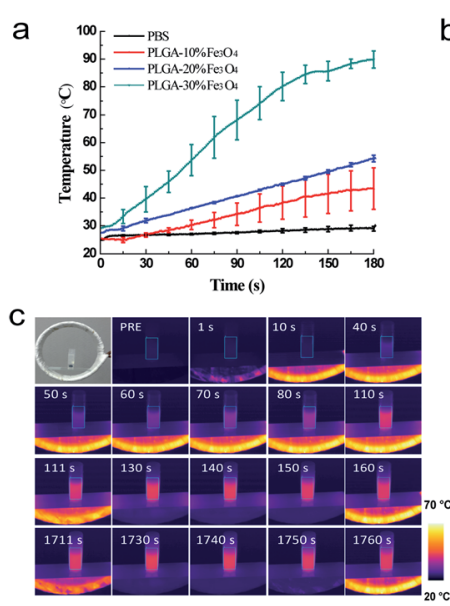

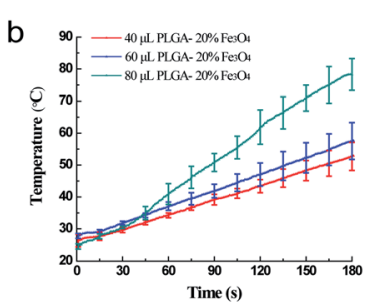

d

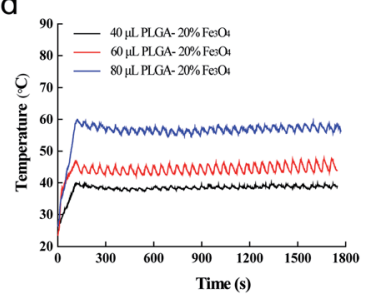

Fig. 2 Heat performance of the implant for magnetic hyperthermia in vitro. (a) In vitro temperature variations after the continuous exposure of saline solution $(1.5 \mathrm{~mL})$ containing $\mathrm{PLGA}-\mathrm{Fe}_{3} \mathrm{O}_{4}$ with different mass fractions of $\mathrm{Fe}_{3} \mathrm{O}_{4}\left(10 \%, 20 \%\right.$ and $30 \% ; 60 \mu \mathrm{L} \mathrm{PLGA} \mathrm{Fe}_{3} \mathrm{O}_{4}$ within $1.5 \mathrm{~mL}$ saline solution) to AMF. (b) The corresponding temperaturetime of the implant at different volumes of implant after continuously exposed to AMF. (c) The thermal images of tube with implanted $60 \mu \mathrm{L}$ PLGA-20\% $\mathrm{Fe}_{3} \mathrm{O}_{4}$ for different intervals after intermittent exposure to AMF. (d) The corresponding temperature-exposure duration curve of $40 \mu \mathrm{L}, 60 \mu \mathrm{L}, 80 \mu \mathrm{L}$ PLGA-20\% $\mathrm{Fe}_{3} \mathrm{O}_{4}$ exposed intermittently to AMF. its appropriate temperature. Next, the temperatures of the implant increased from $52.70 \pm 4.4{ }^{\circ} \mathrm{C}$ to $78.3 \pm 4.95{ }^{\circ} \mathrm{C}$, when the volume of PLGA-20\% $\mathrm{Fe}_{3} \mathrm{O}_{4}$ raised from $40 \mu \mathrm{L}$ to $80 \mu \mathrm{L}$ (Fig. 2b). The results proved that the heating efficiency was positively correlated with the material volume as well.

It is noted that the temperature could easily be higher than $47{ }^{\circ} \mathrm{C}$, which is the temperature threshold for potential tissue ablation. It was reported that the outcome of the thermal damage was dependent on both the temperature and the duration of heating. ${ }^{32}$ Cells become more susceptible to radiation or chemotherapy when their temperature reaches $42^{\circ} \mathrm{C}$ (i.e. hyperthermia). The irreversible cellular damage occurs by heating tissues at $45{ }^{\circ} \mathrm{C}$ for several hours, while the cell death arises by heating tissue at $50-55{ }^{\circ} \mathrm{C}$ for $4-6$ minutes. Nearly immediate coagulation of tissue exists at the temperatures between $60{ }^{\circ} \mathrm{C}$ and $100{ }^{\circ} \mathrm{C}$. At more than $100-110{ }^{\circ} \mathrm{C}$, tissue becomes vaporized and carbonized. ${ }^{35-38}$ By comparison, the heating condition of $50-55{ }^{\circ} \mathrm{C}$ for $4-6$ minutes was the best candidate to avoid excessively high temperature and long heating time. In addition, safe application of AMF to heat magnetic nanoparticles localized in cancer tissue is possible provided the area of exposure and "duty" are controlled. A pulse-timer circuit manufactured by Giltron, Inc., Medfield, Mass was installed allowing 0.5 to 9999 second pulses at any duty $(0-100 \%),{ }^{27}$ defined as:

$$
\begin{aligned}
\text { Duty }= & \frac{\text { pulse ON time }(\text { seconds })}{\text { pulse ON time }(\text { seconds })+\text { pulse OFF time }(\text { seconds })} \\
& \times 100 \%
\end{aligned}
$$

We thus aimed at making the heating temperature rise quickly close to $50-55{ }^{\circ} \mathrm{C}$ and then maintained it for 4 minutes. Finally, we selected $60 \mu \mathrm{L}$ PLGA-20\% $\mathrm{Fe}_{3} \mathrm{O}_{4}$ to do the next study.

After the specific intermittent mode was applied, the temperature of $60 \mu \mathrm{L}$ PLGA-20\% $\mathrm{Fe}_{3} \mathrm{O}_{4}$ reached $45.65 \pm 1.63{ }^{\circ} \mathrm{C}$ in 110 seconds and the fluctuation range was $2.87 \pm 1.08{ }^{\circ} \mathrm{C}$ (Fig. 2d). All data were performed in triplicate. The heating experiment in tubes showed that the temperature was controlled by the combination of the time and the contents of $\mathrm{Fe}_{3} \mathrm{O}_{4}$ nanoparticles. Interestingly, the fluctuation range can be as high as $2.63 \pm 0.68{ }^{\circ} \mathrm{C}$, suggesting that this technique have a great potential to be applied to clinic. Finally, $60 \mu \mathrm{L}$ PLGA-20\% $\mathrm{Fe}_{3} \mathrm{O}_{4}$ was also chosen for the next in vivo experiments.

\section{Heating efficiency in excised bovine liver}

In order to further investigate the magnetic-thermal conversion properties of $\mathrm{PLGA}-\mathrm{Fe}_{3} \mathrm{O}_{4}$ implant, we assessed the ablation efficiency in ex vivo bovine liver using intermittent and conventional continuous heating modes. PLGA-20\% $\mathrm{Fe}_{3} \mathrm{O}_{4}$ was chosen to generate high enough temperature for the coagulative necrosis of ex vivo bovine liver. There are obvious differences between the intermittent and continuous heating group from the thermal images (Fig. 3a-d). The temperature of bovine liver with injection of PLGA-20\% $\mathrm{Fe}_{3} \mathrm{O}_{4}$ increased to $46.4 \pm 4.63{ }^{\circ} \mathrm{C}$ in 40 seconds, and fluctuated within $11.30 \pm 0.36{ }^{\circ} \mathrm{C}$ for 5 minutes, which was consistent with the result of PLGA-20\% $\mathrm{Fe}_{3} \mathrm{O}_{4}$ in PBS 

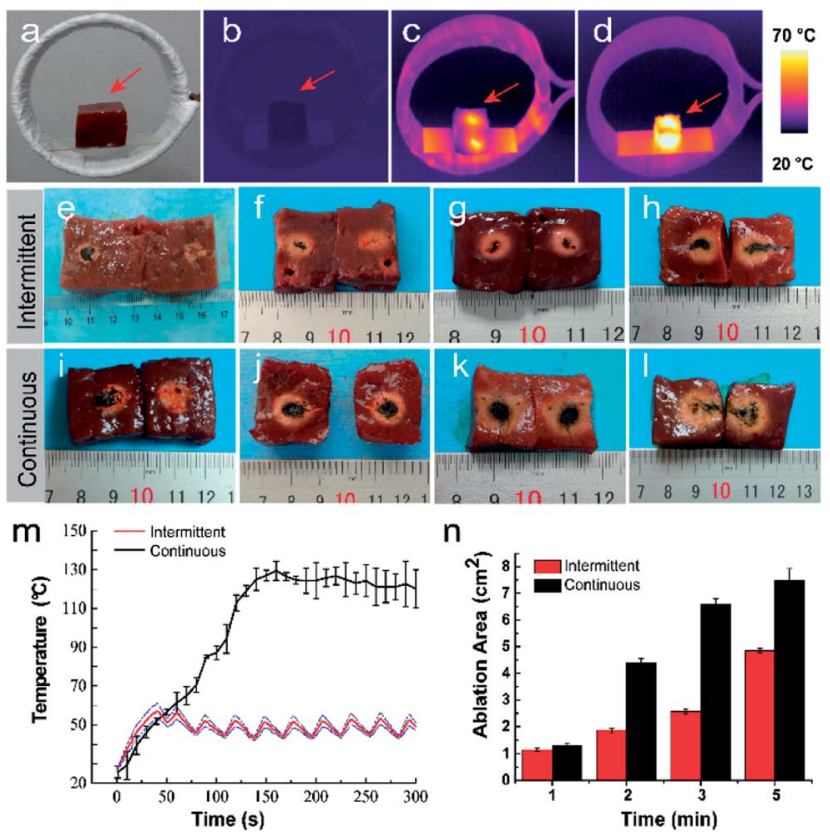

n

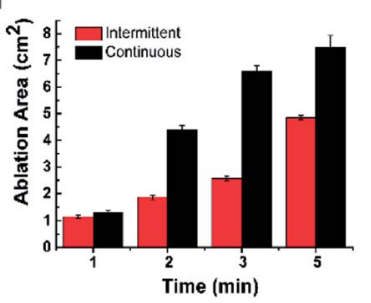

Fig. 3 Heat performance of the implant for magnetic hyperthermia in excised bovine liver. (a) Photographic bovine liver images on the heating coils. (b) The thermal images of bovine liver before heating. (c) The thermal images of bovine liver after intermittent heating. (d) The thermal images of bovine liver after continuous heating. (e-l) Photographic images of ablated tissue volume of bovine liver after exposed to AMF of intermittent and continuous heating group. $(\mathrm{m})$ The corresponding temperature-exposure duration curve of $60 \mu \mathrm{L}$ PLGA-20\% $\mathrm{Fe}_{3} \mathrm{O}_{4}$. (n) The corresponding ablated tissue volume of bovine liver after exposed to AMF.

solution (Fig. 3m). While temperature of the continuous heating group easily exceed $90{ }^{\circ} \mathrm{C}$ about two minutes. The first intermittent time was 10 seconds, and later intermittent time was 20 seconds because of the rapid decline in temperature after continuous heating for 40 seconds. As expected, the ablation area of intermittent heating group increased from 1.14 $\pm 0.07 \mathrm{~cm}^{2}$ for 1 min to $4.85 \pm 0.08 \mathrm{~cm}^{2}$ for 5 min under AMF (Fig. 3e-h and $\mathrm{n}$ ), which were narrower than the continuous heating group (Fig. $3 \mathrm{i}-\mathrm{l}$ and $\mathrm{n}$ ). These results provide guidance for an appropriate ablation dosage and ablation time in further in vivo experiments at some extent. From this experiment, we also know that the heat was generated from the implant and then transmitted to the surrounding area. If the target shape is irregular, the magnetic hyperthermia technique will face the residual problem. In this study, there exist other limitations which need to be further studied as well. For example, only the surface temperature of ex vivo bovine liver was measured by the far-infrared thermometer, which was lower than the real tumor temperature. The optical fiber thermometry or other temperature probe might be useful for the measurement of the internal temperature of the tumor. ${ }^{33}$

\section{In vivo three-dimension ultrasound/CT imaging}

Ultrasound is the popular guidance and monitoring tool for the thermal ablation of cancer due to its safety, noninvasiveness, real-time visualization ability, excellent tissue penetration depth, and low-cost. Computed tomography (CT) confirmed the location between implant and bone in supply. After tumor ablation, ultrasound and CT can show the relative position of the lesion and the ablation areas exactly, and the ablative margin can also be evaluated precisely. To further assess the safety of this therapy, regular and 3D ultrasound were involved. The ultrasound images (Fig. 4a-c) showed that the echo of the tumor was hyperechoic. The hyperechoic implant was clearly visible in ultrasound imaging which guaranteed the precise injection of PLGA- $\mathrm{Fe}_{3} \mathrm{O}_{4}$ into the tumor. After injection, the PLGA- $\mathrm{Fe}_{3} \mathrm{O}_{4}$ appeared hyperechoic inside the tumor tissue, indicating PLGA-20\% $\mathrm{Fe}_{3} \mathrm{O}_{4}$ can be a promising novel ultrasound contrast agent, which can monitor the therapeutic process of tumor. Once the examination was acquired by the 3D ultrasound, the nude mice were divided into three planes to provide 3D sonographic representation of tumor and implant by analyzing software (Fig. $4 \mathrm{e}-\mathrm{h}, \mathrm{S} 3 \dagger$ ): sagittal axis, coronary axis and transverse axis. It precisely showed the position of the implant, which was tightly limited in the center of tumor without significant leaking or deformation. Furthermore, The CT images (Fig. 4d) illustrated that implant with high intensity was inside the tumor, which was consistent with the 3D ultrasound.
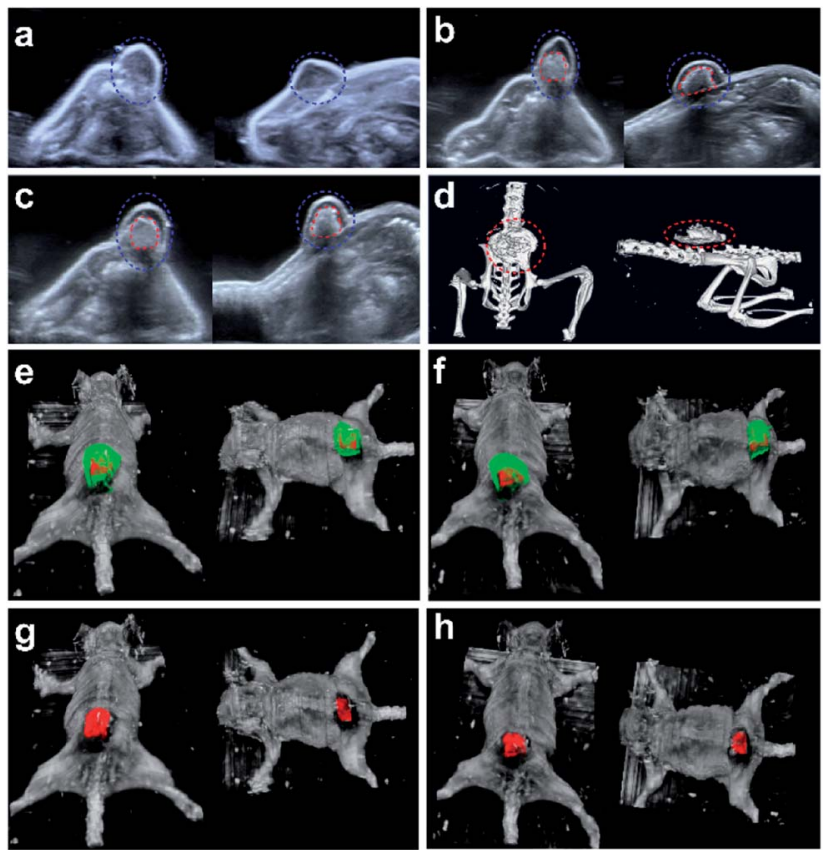

Fig. 4 In vivo 3D ultrasound/CT imaging. The two-dimensional ultrasound transverse section and longitudinal section of implants in vivo. (a) The nude mouse bearing tumor without injection. (b) The same nude mouse received injection of PLGA- $\mathrm{Fe}_{3} \mathrm{O}_{4}$ implant. (c) The nude mouse of $\mathrm{PLGA}-\mathrm{Fe}_{3} \mathrm{O}_{4}$ implant received magnetic hyperthermia ablation. Blue circle: tumor tissue, red circle: PLGA- $\mathrm{Fe}_{3} \mathrm{O}_{4}$ implant. (d) Corresponding computed tomography of nude mice after magnetic hyperthermia ablation. Red circle: PLGA- $\mathrm{Fe}_{3} \mathrm{O}_{4}$ implant. (e and g) The $3 \mathrm{D}$ ultrasound images of implants in vivo before magnetic hyperthermia ablation, and the corresponding 3D ultrasound images hiding the superficial tumor tissue by using software analysis. ( $f$ and $h$ ) The 3D ultrasound images of implants in vivo after magnetic hyperthermia ablation, and the corresponding the same analysis. Green color represents tumor tissue. Red color represents the implant. 
For the bench to bed translation of this novel technique, the safety issue of PLGA- $\mathrm{Fe}_{3} \mathrm{O}_{4}$ should be taken into consideration. The PLGA-Fe $\mathrm{O}_{4}$ was composed of PLGA and $\mathrm{Fe}_{3} \mathrm{O}_{4}$ nanoparticles. Both of them have been authorized by the FDA for clinical application. Further, they were biodegradable in vivo and could be assimilated by physiological metabolism, implying that the PLGA-Fe ${ }_{3} \mathrm{O}_{4}$ should inherit their good safety properties. Meanwhile, according to the results of $3 \mathrm{D}$ ultrasound, this implant did not change its shape significantly during the whole heating process. 3D ultrasound imaging is commonly used in human medicine for different diagnostic clinical applications, ${ }^{34}$ and more safety studies and analysis of 3D ultrasound images of tumor and implant volumes need to be studied in future.

\section{Magnetic hyperthermia efficiency of tumor eradication in vivo}

Such an appropriate electromagnetic energy-heat conversion efficiency is highly desirable for the further in vivo thermal ablation of tumors. The therapeutic potential of this technique was systematically investigated in vivo against nude mice bearing MDA-MB-231 breast cancer xenograft. The thermal images (Fig. 5a) showed that the temperature of the tumor increased with the intermittent exposure time. The corresponding time-temperature curve (Fig. 5b) showed the same trend, which was also accordant with the previous in vitro experiments. The temperature of tumor achieved $55.53 \pm$ $0.50{ }^{\circ} \mathrm{C}$ at 40 seconds, and fluctuated at the range of $6.45 \pm$ $1.34{ }^{\circ} \mathrm{C}$ for 4 minutes. In contrast, the temperature of the tumor
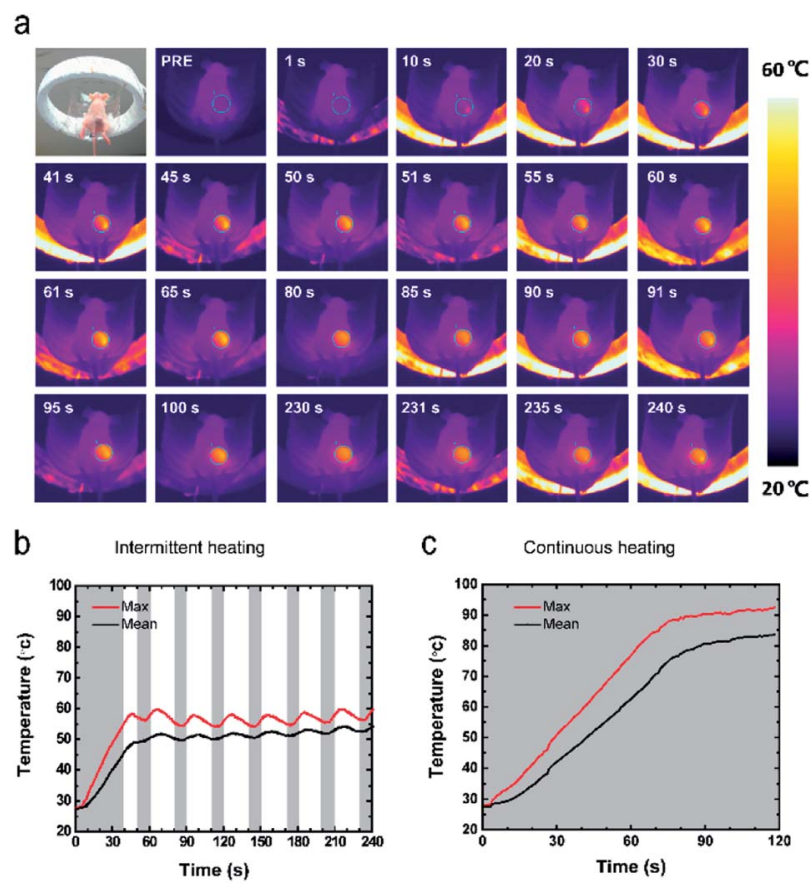

Fig. 5 Heat performance of the implant for magnetic hyperthermia in vivo. (a) The thermal images of tumor-bearing mice at different magnetic hyperthermia stages. (b) The corresponding max and mean temperature-intermittent exposure duration curve of $60 \mu \mathrm{L}$ PLGA$20 \% \mathrm{Fe}_{3} \mathrm{O}_{4}$. (c) The corresponding max and mean temperature exposure duration curve of continuous heating group. rapidly increased to over $90{ }^{\circ} \mathrm{C}$ within two minutes in the continuously heating group (Fig. 5c). The macroscopic image showed the tumor volume was changing with the time after the two different magnetic hyperthermia ablation modes in vivo. In intermittent group (Fig. 6a), the color of the skin on the tumor turned pale immediately after the ablation. And skin was unbroken and intact. A clear boundary between the ablated tissue and the non-ablated tissue could be observed. On the 5th day, the tumor tissue began to form a scab and on the 14th day, the scab began to desquamate. The scab did not separate from mice or fall down until the 18th day. However, in the continuous heating group (Fig. 6b), the color of the skin on the tumor turned pale immediately after the ablation. Some wrinkles of the surrounding skin could be observed. Besides, mice easily awake from anesthesia and try to move. The skin was broken on the first day causing a terrible huge wound. In addition, its diameter of the wound is beyond $2 \mathrm{~cm}$ while the intermittent group' wound diameter is within $1 \mathrm{~cm}$. On the 7th day, the tumor tissue began to form a scab and on the 24th day, the scab desquamated completely. During the first week after being heated, the mice move slower than before. The corresponding time-tumor volume curve (Fig. 6c) revealed that tumor volume decreased with the time after treatment. In the continuous heating group, the tumor fall off completely within three days leaving a big wound and scar. While in the blank control group, the tumor volume had an increasing tendency (Fig. S2 $\dagger$ ). As time went by, the body weights of the mice didn't change significantly (Fig. 6d). Integrated nucleus and cytoplasm were
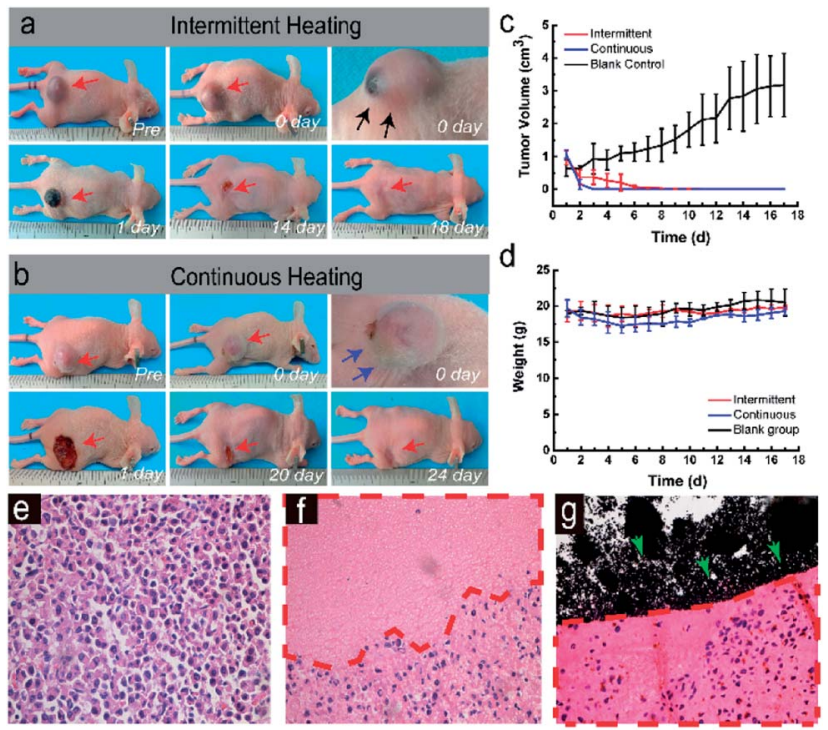

Fig. 6 Magnetic hyperthermia in vivo and microscopic images of the tumor tissue. ( $a$ and b) Photographic images of tumor-bearing mice at different magnetic hyperthermia stages. Black arrows represent intact surrounding skin. Blue arrows represent wrinkles of the surrounding skin. (c) The tumor volume before and after magnetic hyperthermia for different variations. (d) The weight after magnetic hyperthermia for different variations. (e) H\&E staining of blank control group. (f) H\&E staining of continuous heating group. (g) H\&E staining of the intermittent ablated tumor (red dotted line) and its clear boundary between the black implant (green arrows). Images of $\mathrm{e}-\mathrm{g}$ are in the magnification of $\times 400$. 
found in the blank control group while no evident cell destruction was discovered (Fig. 6e). On the other hand, the pathology images showed the significant cell necrosis in the continuous heating group (Fig. 6f). While, there was an obvious difference between the ablated and non-ablated tumor tissue of intermittent heating group (Fig. 6g). Disorder tissue with distinct destructed cells could be observed from the tumor tissue that received PLGA-20\% $\mathrm{Fe}_{3} \mathrm{O}_{4}$ followed by ablation. In particular, the histopathological section showed clear boundaries between the black material and the tumor tissue. This clear boundaries combining the above 3D ultrasound results proved the integrity of material. These pathological results strongly demonstrated the high anti-cancer efficiency of PLGA$\mathrm{Fe}_{3} \mathrm{O}_{4}$ implant under the exposure of AMF. Thus, the high therapeutic efficiency of this unique $\mathrm{PLGA}^{-} \mathrm{Fe}_{3} \mathrm{O}_{4}$ hybrid implant gives a promising clinical translation possibility with the characteristics of simple manufacturing procedure, easily administration with minimal invasiveness, considerably improved patient compliance and high therapeutic efficiency.

Evaluation of blood flow perfusion after ablation by contrastenhanced ultrasonography

The breast cancer was abundant in blood flow in the Color Doppler Flow Imaging (Fig. 7(b, f and g)), and the center was soft shown in the Elastography. When injected $100 \mu \mathrm{L}$ SonoVue, the tumor tissue immediately developed in the way that filled from the peripheral boundary into center within 10 seconds. After the material was injected into the tumor tissue, there still was abundant blood flow in the tumor except the implant in Color Doppler Flow Imaging. However, the center of cancer became hard in the Elastography (Fig. 7(c, g and k)). After being injected into $100 \mu \mathrm{L}$ SonoVue, the tumor tissue still developed in a contrast-enhanced mode (Fig. 7(d, h and l)), implying that the blood flow perfusion of cancer remained, which was equal to alive cancer cells. Nonetheless, ablated tumor showed no significant blood flow and any effective development with constant hard elasticity.

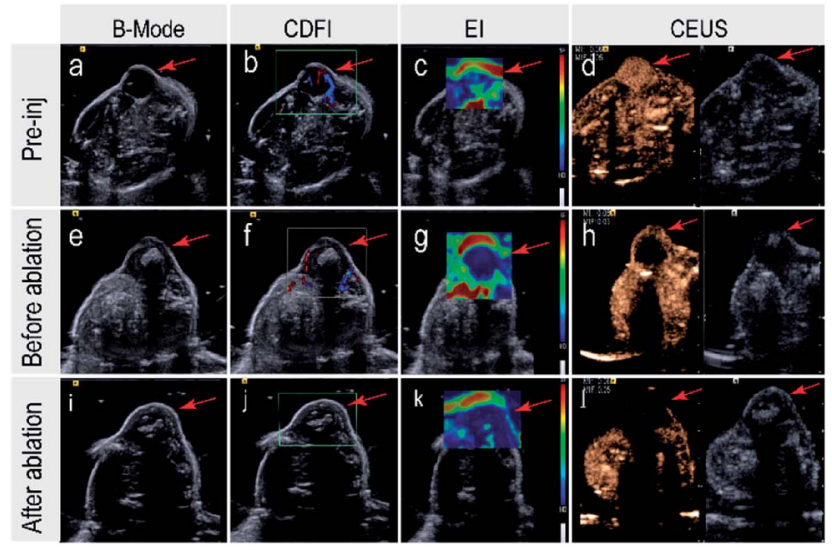

Fig. 7 The ultrasound images of implants in vivo. (a-d) Pre-inj: the nude mice before the injection of materials, $(e-h)$ before ablation: the mice were intratumorally injected into materials. (i-l) After ablation: the nude mice with materials were treated with AMF. CDFI: Color Doppler Flow Imaging. El: elastography. Red: soft tissue. Blue: hard tissue within material. CEUS: contrast enhanced ultrasound.

\section{Conclusions}

In summary, we demonstrated a simple intermittent time-set technique for temperature control magnetic hyperthermia ablation using polylactic-co-glycolic acid (PLGA)- $\mathrm{Fe}_{3} \mathrm{O}_{4}$ implant. The temperature elevation profile upon magnetic hyperthermia both in vitro and in vivo have demonstrated a good controllability. Furthermore, 3D ultrasound and CT guaranteed no significant deformation of implant during the heating process, indicating that the implant was tightly limited in the center of tumor without leaking. H\&E staining of the tumor tissue demonstrated the coagulation necrosis of the ablated tumor. This simple technique successfully avoided the side effects of excessively high temperature and laid a firm foundation for clinical translation of magnetic hyperthermia ablation.

\section{Conflicts of interest}

There are no conflicts to declare.

\section{Acknowledgements}

We acknowledge the financial supports from the National Science Foundation for Distinguished Young Scholars of China (No. 81425014), Key international (regional) cooperative research projects (81720108023), National Natural Science of China (No. 81601506, 81630047, 81227801), Shanghai key discipline of medical imaging (No. 2017ZZ02005 ). All authors contributed to the written manuscript, and they have all approved the final version of the manuscript.

\section{References}

1 R. K. Gilchrist, R. Medal, W. D. Shorey, R. C. Hanselman, J. C. Parrott and C. B. Taylor, Ann. Surg., 1957, 146, 596-606.

2 B. Thiesen and A. Jordan, Int. J. Hyperthermia, 2009, 24, 467474.

3 M. P. Calatayud, E. Soler, T. E. Torres, E. Campos-Gonzalez, C. Junquera, M. R. Ibarra and G. F. Goya, Sci. Rep., 2017, 7, 8627.

4 I. Obaidat, B. Issa and Y. Haik, Nanomaterials, 2015, 5, 63-89. 5 R. Pinol, C. D. Brites, R. Bustamante, A. Martinez, N. J. Silva, J. L. Murillo, R. Cases, J. Carrey, C. Estepa, C. Sosa, F. Palacio, L. D. Carlos and A. Millan, ACS Nano, 2015, 9, 3134-3142.

6 K. Maier-Hauff, F. Ulrich, D. Nestler, H. Niehoff, P. Wust, B. Thiesen, H. Orawa, V. Budach and A. Jordan, J. NeuroOncol., 2011, 103, 317-324.

7 M. Johannsen, U. Gneveckow, L. Eckelt, A. Feussner, N. WaldÖFner, R. Scholz, S. Deger, P. Wust, S. A. Loening and A. Jordan, Int. J. Hyperthermia, 2009, 21, 637-647.

8 J.-t. Jang, J. Lee, J. Seon, E. Ju, M. Kim, Y. I. Kim, M. G. Kim, Y. Takemura, A. S. Arbab, K. W. Kang, K. H. Park, S. H. Paek and S. Bae, Adv. Mater., 2017, 1704362, DOI: 10.1002/ adma.201704362.

9 S. Skalickova, M. Loffelmann, M. Gargulak, M. Kepinska, M. Docekalova, D. Uhlirova, M. Stankova, C. Fernandez, 
H. Milnerowicz, B. Ruttkay-Nedecky and R. Kizek, Nanomaterials, 2017, 7, 435-457.

10 J. M. Giussi, C. von Bilderling, E. Alarcón, L. I. Pietrasanta, R. Hernandez, R. P. Del Real, M. Vázquez, C. Mijangos, M. L. Cortez and O. Azzaroni, Nanoscale, 2018, 10, 11891195.

11 A. Espinosa, M. Bugnet, G. Radtke, S. Neveu, G. A. Botton, C. Wilhelm and A. Abou-Hassan, Nanoscale, 2015, 7, 18872-18877.

12 Q. Zhang, W. Shan, C. Ai, Z. Chen, T. Zhou, X. Lv, X. Zhou, S. Ye, L. Ren and X. Wang, Nanotheranostics, 2018, 2, 87-95. 13 D. A. Vinnik, A. Y. Tarasova, D. A. Zherebtsov, S. A. Gudkova, D. M. Galimov, V. E. Zhivulin, E. A. Trofimov, S. Nemrava, N. S. Perov, L. I. Isaenko and R. Niewa, Materials, 2017, 10, 578.

14 E. Petrescu, C. Cirtoaje and C. Stan, Beilstein J. Nanotechnol., 2017, 8, 2467-2473.

15 P. Moroz, S. K. Jones and B. N. Gray, Int. J. Hyperthermia, 2002, 18, 267-284.

16 K. N. Ekdahl, P. Davoodpour, B. Ekstrand-Hammarstrom, K. Fromell, O. A. Hamad, J. Hong, A. Bucht, C. Mohlin, G. A. Seisenbaeva, V. G. Kessler and B. Nilsson, Nanomed. Nanotechnol. Biol. Med., 2018, 14, 735-744.

17 H. Asem, Y. Zhao, F. Ye, A. Barrefelt, M. Abedi-Valugerdi, R. El-Sayed, I. El-Serafi, K. M. Abu-Salah, J. Hamm, M. Muhammed and M. Hassan, J. Nanobiotech., 2016, 14, 82. 18 Y. Chen, L. Jiang, R. Wang, M. Lu, Q. Zhang, Y. Zhou, Z. Wang, G. Lu, P. Liang, H. Ran, H. Chen and Y. Zheng, Adv. Mater., 2014, 26, 7468-7473.

19 Y. Chen, L. Jiang, R. Wang, M. Lu, Q. Zhang, Y. Zhou, Z. Wang, G. Lu, P. Liang, H. Ran, H. Chen and Y. Zheng, Adv. Mater., 2014, 26, 7468-7473.

20 E. Cazares-Cortes, A. Espinosa, J. M. Guigner, A. Michel, N. Griffete, C. Wilhelm and C. Menager, ACS Appl. Mater. Interfaces, 2017, 9, 25775-25788.

21 S. Kossatz, J. Grandke, P. Couleaud, A. Latorre, A. Aires, K. Crosbie-Staunton, R. Ludwig, H. Dahring, V. Ettelt, A. Lazaro-Carrillo, M. Calero, M. Sader, J. Courty, Y. Volkov, A. Prina-Mello, A. Villanueva, A. Somoza, A. L. Cortajarena, R. Miranda and I. Hilger, Breast Cancer Res., 2015, 17, 66.

22 W. Xie, Q. Gao, Z. Guo, D. Wang, F. Gao, X. Wang, Y. Wei and L. Zhao, ACS Appl. Mater. Interfaces, 2017, 9, 33660-33673.
23 W. Gao, Y. Zheng, R. Wang, H. Chen, X. Cai, G. Lu, L. Chu, C. Xu, N. Zhang, Z. Wang, H. Ran, P. Li, C. Yang, Z. Mei and J. Song, Acta Biomater., 2016, 29, 298-306.

24 Y. Yang, F. Wang, K. Zheng, L. Deng, L. Yang, N. Zhang, C. Xu, H. Ran, Z. Wang, Z. Wang and Y. Zheng, PLoS One, 2017, 12, e0177049.

25 Suriyanto, E. Y. K. Ng and S. D. Kumar, Biomed. Eng. Online, 2017, 16, 36-58.

26 S. Tong, C. A. Quinto, L. Zhang, P. Mohindra and G. Bao, ACS Nano, 2017, 11, 6808-6816.

27 R. Ivkov, S. J. DeNardo, W. Daum, A. R. Foreman, R. C. Goldstein, V. S. Nemkov and G. L. DeNardo, Am. J. Clin. Cancer Res., 2005, 11, 7093s-7103s.

28 A. Makridis, M. Tziomaki, K. Topouridou, M. P. Yavropoulou, J. G. Yovos, O. Kalogirou, T. Samaras and M. Angelakeris, Am. J. Clin. Oncol., 2016, 32, 778-785.

29 M. Moros, A. Ambrosone, G. Stepien, F. Fabozzi, V. Marchesano, A. Castaldi, A. Tino, J. M. de la Fuente and C. Tortiglione, Nanomedicine, 2015, 10, 2167-2183.

30 C. Xu, Y. Zheng, W. Gao, J. Xu, G. Zuo, Y. Chen, M. Zhao, J. Li, J. Song, N. Zhang, Z. Wang, H. Zhao and Z. Mei, ACS Appl. Mater. Interfaces, 2015, 7, 13866-13875.

31 Y. Ling, X. Tang, F. Wang, X. Zhou, R. Wang, L. Deng, T. Shang, B. Liang, P. Li, H. Ran, Z. Wang, B. Hu, C. Li, G. Zuo and Y. Zheng, RSC Adv., 2017, 7, 2913-2918.

32 H. Rhim, S. N. Goldberg, G. D. Dodd 3rd, L. Solbiati, H. K. Lim, M. Tonolini and O. K. Cho, Radiographics: a review publication of the Radiological Society of North America, Inc, 2001, 21 Spec No, S17-S35, discussion S36S19.

33 Y. S. Kim, Am. J. Clin. Oncol., 2015, 31, 225-232.

34 S. Pricking, H. Bollwein, K. Spilker, G. Martinsson, A. Schweizer, S. Thomas, H. Oldenhof and H. Sieme, Theriogenology, 2017, 104, 149-15535.

35 Y. Ling, X. Tang, F. Wang, X. Zhou, R. Wang, L. Deng, T. Shang, B. Liang, P. Li, H. Ran, Z. Wang, B. Hu, C. Li, G. Zuo and Y. Zheng, RSC Adv., 2017, 7, 2913-2918.

36 H. Rhim, S. N. Goldberg, G. D. Dodd 3rd, L. Solbiati, H. K. Lim, M. Tonolini and O. K. Cho, Radiographics, 2001, 21, S17-S35.

37 E. Liapi and J. F. Geschwind, J. Clin. Oncol., 2007, 25, 978986.

38 K. F. Chu and D. E. Dupuy, Nat. Rev. Cancer, 2014, 14, 199208. 